\title{
Can Government be a Good eBayer? The Use of Online Auctions in the Sale of Surplus Property
}

\author{
Enrico Ferro \\ Istituto Superiore Mario Boella \\ Via P. Boggio 63, 10138, Turin, Italy \\ ferro@ismb.it \\ www.enricoferro.com
}

\author{
Lucy Dadayan \\ College of Computing and Information, \\ State University of New York \\ 16 Regina Court, \# 1, Delmar, NY 12054 \\ ld8318@albany.edu
}

\begin{abstract}
E-commerce, and online auctions in particular, represent important examples of how information and communication technologies have been employed by public organizations to gain benefits in both efficiency and effectiveness. While online auctions have widely been used by governments around the world to drive down procurement costs, they have been seldom used as means for revenue maximization. In this article, we discuss the three-year experience gained by New York State in the use of online auctions for the sale of surplus inventory and property. This case study, besides representing an example of a best practice for other US state and local governments as well as European Governments, also provides an interesting starting point to address a number of research questions such as the ability of governmental organizations to meet private sector standard; the measurement of returns on Information and Communication Technology (ICT) investments; and the new possible roles played by transparency in the migration toward online models.
\end{abstract}

\section{Introduction}

Auctions are an ancient practice. The first documented use of auctions was dated at $500 \mathrm{BC}$, when Babylonians sold young slaves during open markets. As Wyld [25] noted, "the very concept of a 'fixed' price for a good or service is - in historic terms - a relatively recent development." The reason auctions have survived throughout history may be attributed to a number of benefits it provides. From a buyer's standpoint, auctions represent an efficient allocation mechanism, since they allow items to be sold to bidders with the highest valuation. From a seller's standpoint, they permit a maximization of the revenues stemming from an item's sale.

Historically, governments have practiced live and sealed-bid auctions in various domains of their activity. With the advent of information and communication technologies and the implementation of digital government, reverse auctions were seen by many governments in the United States as interesting opportunities for reducing procurement costs. By aggregating demand and increasing competitive pressure among suppliers, it was possible to attain a significant increase in bargaining power.

While widely used in cost reduction activities, online auctions have been scarcely considered by governments for revenue maximization purposes. There are a number of reasons for this: the inherent lack of profit orientation present in governmental organizations, the presence of a significant inertia among both state employees and bidders towards the migration to an online model, and the difficulty in reaching critical mass in terms of bidders required for online-auctions to outperform traditional live auctions.

This article will focus particularly on the three-year experience gained by the State of New York in selling its surplus inventory and property via eBay, one of the biggest online communities in the world. This case study, in addition to representing a best practice in the use of online auctions for revenue maximization in government, also constitutes an excellent example of 
complementarity among eBusiness and eGovernment activities.

\section{Objectives}

The aim of this paper is threefold:

1. Use the three-year experience gained by New York State to conduct a longitudinal analysis of benefits and barriers related to the use of online auctions in sale of surplus property.

2. Identify lessons learned and provide a concrete working example that may be used as a best practice for the implementation of similar activities.

3. Use the results emerging from the case study to provide preliminary answers to the following questions: Can government agencies meet private sector quality standards? What returns on investments can agencies investing in online auctions expect to enjoy? What new roles can transparency play in the migration toward an online model of government?

\section{Methodology}

The research purpose of this paper is primarily exploratory since it is our intention to investigate how and whether governments can become more efficient and effective in utilizing an eBay model for surplus auctions. We adopted both a quantitative and qualitative approach, which helped us to understand how the eBay model is used in a government setting.

The methodology adopted is a case study. An interview was conducted with the assistant director of the Property and Fleet Administration Department of the Office of General Services in the New York state.

Also, quantitative data were collected from both the Office of General Services' SAP-pro system, as well as the Office of General Services' information publicly available eBay account.

New York was chosen as a case study for a number of reasons:

1. It is considered a best practice in the use of online-auctions at state government level. Few similar initiatives are present in the United
States, most of which are carried out at the local government level.

2. It constitutes a successful example of collaboration between the private and public sector, thus reinforcing the notion of complementarity among eGovernment and eBusiness activities.

Finally, we conducted library and online research and gathered relevant data from working papers, journals, newspaper archives, various databases, and other related sources.

\section{Literature Review}

The New York State experience results are of particular relevance in a time when a number of global trends are generating significant shortfalls in governments' budgets. On the one hand, longer life expectancies and low birth rates have contributed to an increase in the percentage of elderly people and their related healthcare costs. On the other hand, citizens and businesses expect the quality of public services to meet more and more private sector standards. These opposing forces have put pressure on public organizations and made streamlining and optimization activities key for their survival.

Throughout the last decade, in an attempt to increase the efficiency of government processes, significant investments have been made to promote public organizations' digitalization. Nevertheless, to date there is still very little evidence of the returns that these investments have yielded. No agreement has been reached about an objective and comprehensive methodology for return on investment assessments of information technology investments. In this respect, the manageability of information produced by online auctions represents an interesting opportunity to carry out a reasonably accurate analysis.

According to Wyld [25], the auction model can be applied to governmental operations in three different realms: (1) governmental procurement, (2) disposition of used/surplus/seized governmental assets, and (3) internal allocation of resources. The intent to adopt online auctions for the sale of excess property may be dated back to 1999-2000, although the passage from will to action is decidedly more recent. The first research works on this subject assumed that governments would have relied on circuits or communities composed of corporations with the purpose of getting rid of useless and unwanted products [25]. The main concern was whether the 
proliferation of these ad hoc communities would have reached the necessary critical mass to make online auctions to work. Nobody could foresee the use of a more general network such as eBay as a potential solution to this problem.

Over the last few years the commercial success of eBay became apparent to the general public. According to Krishnamurthy [13], eBay's direction of growth is in foreign markets and "it is currently operating in eight of the top ten countries by online market size outside of the U.S. It is gaining users 50\% faster in Europe than in the U.S., and gross merchandise sales are growing 135\% faster." In the United States, many state and local government agencies have recognized eBay's success as well, and initiated their own online versions of eBay. The Government Liquidation website was created with functions similar to eBay, and is the exclusive partner of the U.S. Department of Defense for the sale of surplus property. However, there are also a number of state and local government agencies that chose to use eBay instead for selling surplus and seized governmental assets.

As Wyld [26] noted, eBay, the largest online emarketplace, "attracts many state and local governments selling all manner of surplus goods, either direct or through intermediaries." A few government entities have been active eBay sellers including states (California, Colorado, New York, Oregon, Pennsylvania, and Texas), counties (Palm Beach- FL, Ventura-CA) and universities (Oregon State University). As Exhibit 1 depicts, in 2003 over $10 \%$ of cities and counties and approximately $4 \%$ of municipal utilities' local governments across the country were already using online auctions for selling surplus equipment and materials.

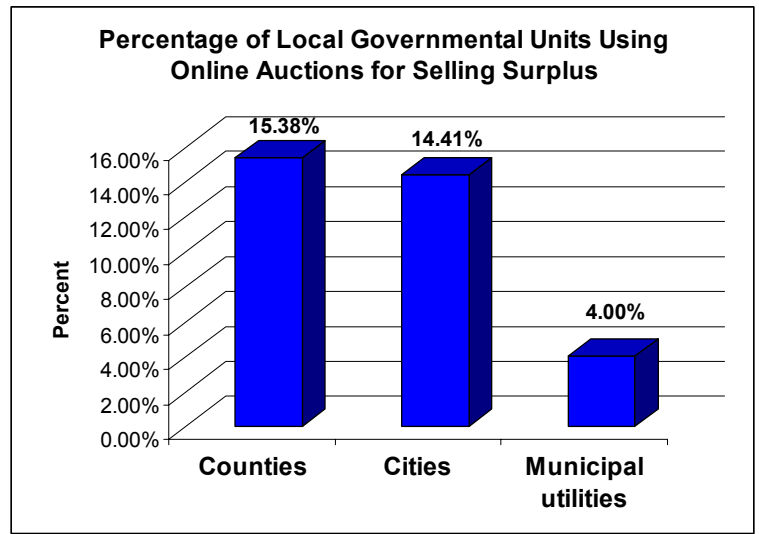

Exhibit 1

Source: Purchasing 2003 Benchmarking Survey, National Institute of Governmental Purchasing
Gradually, eBay has become a platform for the above mentioned government entities, allowing them to turn unclaimed items, end-of-life assets, fleets of vehicles, or other property into monies for treasury.

eBay almost exclusively relies on its feedback mechanism to build trust and encourage good behavior from its members. Feedback is analyzed, aggregated, and made available to the public through member feedback profiles. Dellarocas [7] intended to explain "to what extent binary reputation mechanisms, such as the one used at eBay, are capable of inducing efficient market outcomes in marketplaces where (a) true quality information is unknown to buyers, (b) advertised quality is completely under the control of the seller and (c) the only information available to buyers is an item's advertised quality plus the seller's feedback profile."

According to Dellarocas [7], if binary feedback profiles are used to measure the extent to which a seller advertises truthfully, then, in theory, binary reputation systems can be well-functioning, provided that buyers strike the right balance between rating leniency and quality assessment strictness. Interestingly, "judging seller trustworthiness based on their negative ratings is preferable to basing it on their positive ratings and some degree of rating leniency helps bring stability to the system." Binary reputation mechanisms may not function well if buyers do not use the "right" threshold parameters when they judge seller profiles. Thus, we may end up having a well functioning binary reputation mechanism in theory, which is quite fragile in practice. As Dellarocas noted [7], the "right" judgment rule is difficult to infer correctly from knowledge of the sum of positive and negative ratings alone, which is the only information currently provided by eBay to its members. LuckingReiley et al. [15] noted that although seller reputation points on eBay have a measurable effect on auction prices, negative ratings matter considerably more than positive ones.

We would like to add that even if enough information is provided for making the "right" judgment, buyers will still face the problem of making the "right" judgment, due to lack of capacity to do so, as well other interfering factors such as being intrigued by the product and ignoring information, and getting into the mode of gambling since online auction bidding for many buyers can be considered as a type of gambling. 
Houser and Wooders [10] found that eBay's seller reputation "is a statistically and economically significant determinant of auction prices." Data analyses done by Houser and Wooders, as well as others suggest that reputation building is an important issue in online auctions. Thus, government agencies as sellers shall strive to provide a good service to get a good reputation and, in turn, get higher prices. Finally, as many studies showed, a good reputation is a good predictor of performance.

\section{Case Analysis}

In October 2001, New York State approved a pilot project for the sale of excess property via online auctions. This project was initiated directly by the Governor. Its implementation was highly supported and followed a top-down approach. The aim of the Governor was twofold:

1. Streamline and make the existing process for the disposal of excess property more efficient and effective.

2. Provide an easier access to the public for this type of service, taking advantage of the opportunities offered by information and communication technologies.

The Office of General Services is the body in charge of managing the sale of all excess property belonging to the approximately 150 agencies present in the state of New York. All state agencies are obliged by law to go through the Office of General Services for the disposal of their excess property. The revenue generated by these sales are collected in a general fund that is subsequently redistributed among all agencies' budgets.

Excess property is state property that is outdated, damaged, unused, or obsolete. It is property that cannot be of any use to the government and should be disposed of.

Until 2002, live and sealed bid auctions have been the only selling methods adopted by the Office of General Services. Although reasonably effective, these techniques present a number of drawbacks:

1. Live auctions are highly influenced by weather conditions. The number of bidders taking part in a live auction may be significantly reduced by inclement weather. Fewer bidders has an obvious negative impact on the average closing price and overall total revenue. Moreover, due to high transportation costs, live auctions are usually attended only by local bidders.

2. In sealed-bid auctions, bidders are required to advance ten percent of their offer. This means that all non-winning bidders need to be reimbursed. This is both a costly and timeconsuming process.

3. Both sealed-bid and live actions have a leadtime of about two months.

In October 2001, the Office of General Services launched a pilot project to test the use of online auctions. The e-Bay community was chosen as a test bed because of its worldwide reach and its capillary diffusion in the United States. The first online sale took place in October of 2002, about a year after a set up time that required involvement of three Office of General Services' full-time employees and eBay technical staff. Since then, the number of online sales made through auctions has experienced significant year over year growth rates. As evidenced in exhibit 2, the Office of General Services' sales increased from 153 items in 2002 to 1,215 items in 2004, resulting in a $790 \%$ growth increase in only a three year period.

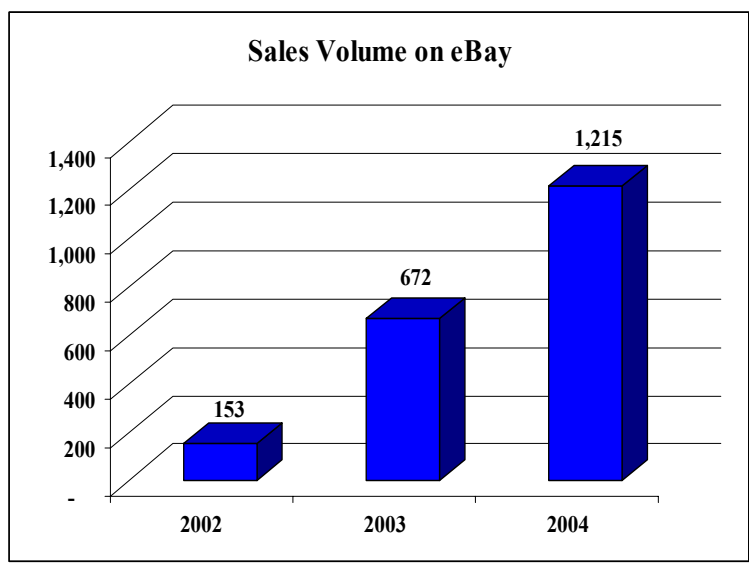

Exhibit 2

Source: New York State's Office of General Services

Exhibit 3 shows that revenues from eBay's online auctions grew even faster than sales' volume. Revenues experienced a fourfold increase in the last year. This may be attributed to a higher level of 
confidence, which in turn, resulted in the sale of items with a higher unit price.

A fast growth in sales was not the only effect of online auctions. The limited number of bidders previously reached through sealed-bid and live auctions did not permit the Office of General Service to sell all the surplus property received by state agencies. This generated additional costs stemming from missed sales and disposal services for unsold property.

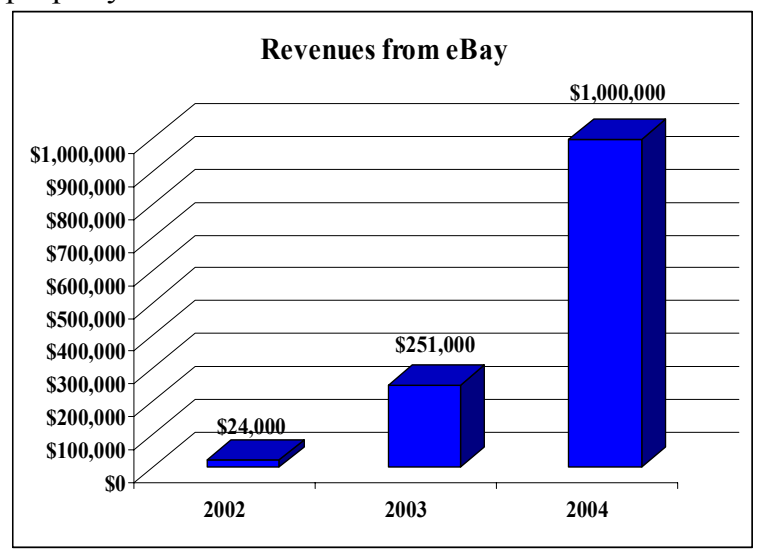

Exhibit 3

Source: New York State's Office of General Services

Online auctions eliminated both of these costs. Additionally, the wide variety of bidders present in the eBay community allows the Office of General Services to get rid of all excess property without exception. This helps to generate extra revenue, as well as helps to eliminate disposal costs. Finally, efficiency gains are a further benefit generated by this new system. The average lead-time for items' disposal has shortened from two months to about three weeks.

A legitimate question could be raised as to how much a state should expect to gain from implementing a system similar to the one adopted by New York State. Although an exact answer may not be possible, we believe that a good approximation may be attained. As shown in exhibit 4 , by adopting online auctions, the Office of General Services has increased its return on investment by nearly five times.

When the sealed bid system was in place, the return of each dollar spent was $\$ 12.78$ in revenues. Now, with online auctions, every dollar spent generates a $\$ 56.75$ return. However, these figures do not account for efficiency gains and the cost reduction due to elimination of disposal costs associated with

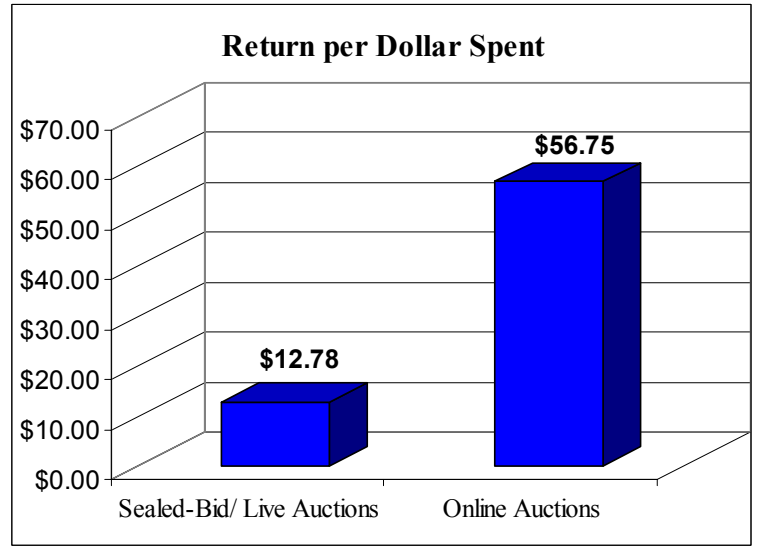

Exhibit 4

Source: New York State's Office of General Services

unsold property. In this respect, the data presented here represents a slight underestimation of actual returns. Nevertheless, we believe this analysis provides a reasonably accurate estimation of the returns that the Office of General Services has enjoyed subsequent to its investments - mainly in personnel time - to set up the new system for the sale of surplus property on eBay.

The adoption of online auctions did not only bring satisfying results, but also brought problems that needed to be solved. A first barrier to implementation was a high level of inertia present among traditional bidders, as well as state agencies. To tackle this problem, the Office of General Services organized workshops to explain the advantages of using online auctions. Understanding the amount of time that could be saved helped them to overcome their reluctance.

The training provided during these workshops was not just aimed at overcoming inertia. It also served to reduce the workload in terms of communications with interested bidders because of incomplete descriptions provided by state agencies. At first, sales were managed centrally by the Office of General Services, but to reduce transportation costs and provide an incentive for more complete descriptions, logistics have been redistributed. Delegating the communication burden onto state agencies encouraged them to provide more accurate and complete descriptions to the Office of General Services.

Another important factor that contributed to increased usage of online auctions by state agencies was the presence of a high level of transparency in the eBay system. Having the ability to check the types of products sold by all agencies via the Office of General 
Services fostered an awareness that a wide number of unused or obsolete items could be sold to generate revenues and avoid disposal costs.

Currently, the Office of General Services does not use sealed bid auctions any longer. Online auctions represent about $50 \%$ of the volume in terms of items. The remainder consists of live auctions (25\%) and transfers among agencies $(25 \%)$.

It is interesting to note that general public represents the majority of buyers (about $75 \%$ ), while corporate customers make up only $25 \%$ of buyers. In this respect, adopting a platform like eBay with a wide diffusion among the general public, rather than an alternative platform more oriented towards small and medium enterprises seems to have been a wise choice. Requiring an additional account on an alternative circuit or community would have most likely resulted in a lower potential "market."

In terms of geographical dispersion, about $90 \%$ of buyers are located in New York or the surrounding states, while the Office of General Services has buyers from as far as Sweden. This suggests that eBay's vertical penetration is an important factor and that the introduction of online auctions did not have a significant impact on the geographical composition of buyers. This could be due to a number of reasons. First, it may be because of the structure of the eBay system. The auction company rather than creating a single worldwide community has preferred to create a network of local communities that are interconnected among themselves but with looser ties. It is a firm belief of eBay that context and locality should play a significant role in online communities. Second, the fact that Office of General Services has not provided any shipping service for the goods sold via the eBay account could have also played a role. Although bidders unable to collect the items bought directly from the warehouse may still arrange for a shipping service remotely, the cost in terms of time as well as knowledge required could probably represent a barrier for many bidders. Nevertheless, it must also be noted that for certain categories of products with a high unit value or niche markets (i.e. boats, airplanes, vintage cars), the worldwide breadth of eBay has proven to be a key factor and the lack of a shipping service did not represent a barrier at all.

As already stated, online auctions have partially replaced the use of live auctions and completely replaced sealed bid auctions in the last three years. Forrester Research anticipates that by 2006 approximately 40 percent of all business-to-business commerce will be transacted online [25].

The application of evolutionary theory to technological adoption and development [14], tells us that substitution effects are only a first step in the process that an organization (or a system) has to go through when adopting a new technology. Second order effects such as innovation and co-evolution start to appear over time as the organization adopting the technology becomes more mature. The experience acquired by the Office of General Services in the last three years constitutes an important asset that could be used as a stepping stone to diversify or enlarge the Office of General Services' activities. This is proved by the fact that they have been asked by several authorities, including the Throughway Authority, to provide the same service offered to state agencies. This, besides recognizing the value and quality of the Office of General Services' work, also represents an interesting opportunity to generate new revenue.

Another example of potential innovation could be represented by the creation of hybrid live auctions, which are live auctions combined with online auctions. This could be an example of possible future developments in co-evolution terms of live and online auctions. Such practices could take advantage of the benefits that new technologies offer and at the same time guarantee fair access to all citizens without excluding those who lack sufficient levels of digital literacy and computer skills.

The level of governmental use of and involvement in online auctions depends on many factors including e-business, public attitude, legislative and regulatory changes, cultural changes, technology, and inter/intragovernmental cooperation among others, as noted by Wyld [25]. Even though the road to becoming a "good eBayer" for the government is long and potentially risky, the forecasted savings could be significant. It is projected that the private sector can save between 18 to 45 percent with e-marketplaces. And if the public sector could reach half of its forecasted savings potential, this would still be a great success [26].

\section{Conclusions}

Probably the most significant result emerging from this case study is the opportunity to increase the revenue generated by the sale of surplus inventory and property through online auctions nearly five fold. 
A second conclusion that may be drawn involves the introduction of performance incentive systems in the public sector. During the interview conducted at the Office of General Services, it was discovered that the presence of a feedback process on each transaction was an effective incentive that raised the quality of their customer service, as well as increased the efficiency of the entire sale process. Although the feedback system present on eBay has been primarily devised as a solution to a trust issue, it also proved to be an effective way for New York State to maintain high customer service standards. As previously stated, high rates of positive feedbacks correlated positively with higher closing prices. All this leads us to believe that a high level of interaction (and perhaps, integration) between state-owned and private organizations, coupled with the appropriate incentive systems, may lead governmental organizations to meet private sector standards in terms of performance in spite of the non-competitive role played in the market. This seems to be feasible, and as Wyld [26] noted "the biggest experiment in public sector reverse logistics today, where the American military is transforming the way surplus is sold through an innovative publicprivate partnership."

The analysis of the case study also cast a new light on the role of transparency in government processes. In the literature, the transparency of government processes has been conceived as an important objective to guarantee correct management of internal processes. In other words - it has been perceived as a control system. Reichard [18] claims that the more transparent an organization's web site is, the more it is willing to allow citizens to monitor its performance. New York State also revealed transparency to be an important catalyst for mutual learning among agencies. The possibility for each agency to have the opportunity to consult the list of surplus property sold through Office of General Services by other agencies fostered a circulation of ideas and examples, thus generating a mutual learning process.

Another interesting aspect that emerges from the New York State case study concerns the choice of the service provider. The choice of provider is also a mechanism for driving productive efficiency.

To answer the question posed in the title of the article, government not only may — but should — be a good eBayer. To be successful in the eBay community it is necessary to meet two key requirements: (1) generate a high volume of transactions and, (2) perform a good service, which is measured by a high percentage of positive feedbacks. Government consumption in western countries amounts to about $20 \%$ of the gross domestic product. This generates an enormous amount of surplus due to obsolescence, damage, and/or downsizing. In this respect, government has the potential to be not only a power-seller but a "mighty-seller." Moreover, the New York State experience showed that when the adequate context and incentives are in place, government agencies can meet private sector standards both in terms of efficiency and customer service.

In conclusion, the research presents an interesting opportunity for government organizations to reduce the pressure on their budgets by significantly increasing the revenue generated by the sale of surplus property. Nevertheless a number of questions still remain unanswered concerning the applicability of this model in different social and legal contexts. Further research should aim at answering those questions, identifying possible viable alternatives, and measuring not only the financial aspect of return on investment in online auctions, but also the political and social aspects of return on investment.

\section{Bibliography}

[1] Bapna R., Goes P., and Gupta A. "Online Auctions: Insights and Analysis" Communications of the ACM 44 (11), p. 42-50, 2001.

[2] Brean H. "UPDATE: Internet Auctions of Confiscated Goods Generating Money for Boulder City” Las Vegas Review-Journal (April 19, 2004)

[3] Brown, R. "E-Gov Outsells Amazon: Uncle Sam Presides Over a G2B Bazaar Online." Line56 (July/August): 21, 2001

[4] Caniglia, J. "Marshals Hope Online Auction Grows into Big Moneymaker.” The Cleveland Plain Dealer (May 1, 2003)

http://www.cleveland.com/search/index.ssf?/base/news/105 1782219113470.xml?nohio.

[5] Cowan, L . "Dead Dot-Coms Mean Plenty of Booty for Auctions." The Wall Street Journal Online (January 9, 2001). 
[6] Cronin, P. “Town Considers Holding Auction.” The Hampton Union April 27,

http://www.seacoastonline.com/news/hampton/04272004/n ews/13012.htm.2004

[7] Dellarocas, C. "Analyzing the Economic Efficiency of eBay-like Online Reputation Reporting Mechanisms." Sloan School of Management, MIT, 2001. http://ccs.mit.edu/dell/ec01ebay.pdf

[8] Dysart, J. “Government Employ Online Auctions to Buy and Sell." Government Technology International, 2003.

http://www.centerdigitalgov.com/international/story.php?do cid $=77525$

[9] Fleming, S. "Online Auctions Help Sell Surplus Property” ISSN: 0149-337; 2004.

[10] Houser, D. and Wooders, J. "Reputation in Auctions: Theory, and Evidence from eBay." Working Paper, University of Arizona, 2000.

http://bpa.arizona.edu/ jwooders/ebay.pdf

[11] James D., Jr., and Spier. "Designing a Private Industry: Government Auctions with Endogenous Market Structure." Journal of Public Economics, 53: 127-147 1994

[12] Joya, L. Zamot F. "Internet-Based Reverse Auctions by the Brazilian Government" The Electronic Journal on Information Systems in Developing Countries EJISDC (2002), 9, 6, 1-12

http://www.is.cityu.edu.hk/research/ejisdc/vol9/v9r6.pdf

[13] Krishnamurthy, S. “A Comparative Analysis of eBay and Amazon." In "E-Commerce Management: Text and Cases." University of Washington, USA, 2004. http://faculty.washington.edu/sandeep/d/amazonebay.pdf

[14] Leydesdorff, L., Van den Besselaar. "Technological Developments and Factor in a Non-Linear Model." Journal of Social and Evolutionary Systems, 21, 1998 http://hcs.science.uva.nl/usr/peter/publications/jses98. $\underline{\mathrm{rtf}}$

[15] Lucking-Reiley, D., Bryan, D., Prasad, N. and Reeves, D. "Pennies from eBay: The Determinants of Price in Online Auctions." Working Paper, Vanderbilt University, 2000.

http://www.vanderbilt.edu/econ/reiley/papers/PenniesFrom EBay.pdf

[16] Moschella, D. "Online Auctions: The Exception Not the Rule. ” Computerworld, 1999
[17] Perlman, E. “Going, Going....click.” Governing City \& State Magazine, 2001

http://www.governing.com/archive/2001/nov/techtalk.txt

[18] Reichard, C. "The Impact of Performance Management on Transparency and Accountability in the Public Sector." In Annie Hondeghem, ed. Ethics and Accountability in a Context of Governance and New Public Management. IOS Press, The Netherlands, 1998

[19] Tibbetts, J., Bernstein B. "Online Auctions: The Human Factor. ” Information Week, 2000

[20] Vallone, J. “Going Once... Going Twice...” Entrepreneur, 2000

[21] Vigoroso, M. “Are Internet Auctions Ready to Gear up?” Purchasing 126, 1999

[22] Welch, E., Hinnant C. "Internet Use, Transparency, and Interactivity Effects on Trust in Government." Proceedings of the 36th Hawaii International Conference on System Sciences (HICSS'03) http://ieeexplore.ieee.org/iel5/8360/26341/01174323.pdf

[23] Wilder, C. "Unload Your Surplus on the Web." Information Week, 1999

[24] Wood C. "Risk and Return in Online Auctions.” The Electronic Journal on Information Systems in Developing Countries EJISDC (2002), 9, 6, 1-12

http://www.nd.edu/ cwood1/research/RiskReturn.pdf

[25] Wyld, D. "The Auction Model: How the Public Sector can Leverage the Power of eCommerce Through Dynamic Pricing." Southeastern Louisiana University, 2000 IBM Center for the Business of Government. http://www.schaubroeck.be/informatica/egovernment/endo wm.eproc.PDF

[26] Wyld, D. "Government Garage Sales: Online Auctions as Tools for Asset Management." Southeastern Louisiana University, 2004, IBM Center for the Business of Government http://www.businessofgovernment.org/pdfs/WyldReport3.p df 